\title{
Assessment of Post Graduate Medical Education: Global
}

\author{
QT ISLAM
}

(J Banagladesh Coll Phys Surg 2015; 33: 32-40)

\section{Introduction and Background}

In education, the term assessment refers to the wide variety of method that educators use to evaluate, measure and document the academic readiness. Learning progress and skill acquisition of student from preschool through college and finally in Post Graduate level at adulthood.

White assessments are after equated with traditional tests especially the standardized tests, successful acquisition of particular skill and knowledge, the understanding and recall of facts, ability to analyze are assessed.

Assessment has different dimension and directions used in different form in different examination ${ }^{1}$.

1. Standardization assessment: Designed, administered and scoured in a standard or consistent manner.

2. High-stakes assessment: Typically standardized tests used for the purposes of accountability.

3. Standards- referenced or standards-based assessments: Designed to measure how well students have mastered the specific knowledge and skills described in local, state or national.

4. Pre-assessments: Administered before students begin a lesson, unit, course or academic program.

5. Formative assessments: In-process evaluations of student learning that are typically administered multiple times during a unit, course or academic program.

6. Summative assessments: Are used to evaluate student learning at the conclusion of a specific instructional period.

7. Interim assessments: Use to evaluate where students are in their learning progress and determine whether they are on track to performing well on future assessment.

Address of Correspondence: Prof. Quazi Tarikul Islam, Professor of Medicine, Honorary Controller of Examination, Bangladesh College of Physicians and Surgeons, Email: prof.tarik@gmail.com

Received: 1 October, 2014

Accepted: 20 December, 2014
8. Common assessments: Are collaboratively developed by groups of educators who agree on a common format and purpose for the assessments and who administer them in consistent ways.

9. Performance assessments: Typically require students to complete a complex task.

10. Portfolio-based assessments: Are collections of academic work- assignments, lab results, writing samples, speeches, art projects, websites.

11. Placement assessments: Used to 'place' students into a course, course level or academic program.

12. Screening assessments: Used to determine whether students may need specialized assistance or services or whether they are ready to begin a course, grade level or academic program.

So, many assessment procedures are available but in Post Graduate medical education few are used in different countries to achieve final degree.

It might differ from country to country and in a same country from institution to institution but grossly varies in terms of assessment in USA, UK, Australia, Canada with that of the South East Asian countries².

According to Sir John Bagot Glubb, Syed Faride and S. M. Imamuddin, the first medical schools to issue academic degrees and diplomas were the teaching Bimaristan(Hospitals) of the medieval Islamic world. The first of these institutions was opened in Baghdad during the time of Harun al-Rashid. They then appeared in Egypt from 872 and then in Islamic Spain, Persia and the Maghreb thereafter. Physicians and surgeons at these hospital-universities gave lectures on Medicine to medical students and then a medical diploma or degree was issued to students who were qualified to be practicing physicians ${ }^{3}$.

\section{Methods:}

The review article is based on systematic search through Pubmed and other search engine like google and google scholar. The existing curriculum and assessment system ( online based) of different countries were also searched 
for analysis. The English literature was only chosen. The personal communication was also included for retrieving the documents for review.

\section{A. In the USA \& Canada}

\section{Purpose}

The USMLE assesses a physician's ability to apply knowledge, concepts, and principles, and to determine fundamental patient-centered skills that are important in health and disease and that constitute the basis of safe and effective patient care. Examination committees composed of medical educators and clinicians from across the United States and its territories prepare the examination materials each year.

\section{Overview}

Students and graduates of U.S. or Canadian medical school programs accredited by either the Liaison Committee on Medical Education (LCME) or Committee on Accreditation of Canadian Medical Schools, leading to the Doctor of Medicine (M.D.) degree, register for Step 1 and Step 2 of the USMLE with the NBME. Students and graduates of medical schools outside the United States or Canada register for Step 1 and Step 2 with the Educational Commission for Foreign Medical Graduates (ECFMG). Graduates of medical schools in and outside the United States and Canada register for Step 3 with the FSMB or with a medical licensing authority in the United States. Each of the three steps of the USMLE examination complements the other; no step stands alone in the assessment of readiness for medical licensure. The USMLE program recommends that for Step 3 eligibility, licensure authorities require the completion, or near completion, of at least one postgraduate training year in a program of graduate medical education accredited by the Accreditation Council on Graduate Medical Education (ACGME) ${ }^{4}$.

All three steps of the USMLE exam must be passed before a physician with an M.D. degree is eligible to apply for an unrestricted license to practice medicine in the United States. After completion of USMLE candidates required to go for residency training program. This program duration varies from subject to subjects between 4 and 8 years. Then only the candidates is considered as post-graduate doctor.

\section{Step 1}

USMLE Step 1 assesses whether medical school students or graduates understand and can apply important concepts of the basic sciences to the practice of medicine. As of 2007, it covers the following subjects, in both systemic (general and individual anatomical characteristics) and procedural (functional, therapeutic, environmental, and abnormality) themes:

Pathology, Pharmacology,,Physiology, Microbiology, Biochemistry, Anatomy, Behavioral sciences, Interdisciplinary topics, such as nutrition, genetics, and aging.

US medical students take Step 1 at the end of the Basic Sciences portion of the curriculum, usually after the second year of medical school. It is an eight-hour computer-based exam consisting of 322 multiple-choice questions (MCQs) divided into seven blocks each consisting of 46 questions. As of summer 2008, some questions include audio and video. Each block must be finished within an hour. An optional tutorial about how to use the computer program of the exam is offered at the beginning of the exam and takes 15 minutes. This time is deducted from the hour of allotted break time. A quality assurance survey is presented at the end, provided some of the original eight hours is left over.

Scores are reported as both a three-digit score and twodigit score. However as of July 1, 2011 only the 3-digit score is reported on USMLE transcripts. The two-digit score is not a percentile, as many test-takers have been known to erroneously report, but is instead an obsolete scale still used internally by some state medical licensing authorities. On January 1, 2014, the passing score was raised from 188 to 192 . The mean and standard deviation for first-time examinees from US and Canadian medical schools, as of July 2014, are 228 and 21 , respectively, with most scores falling between 140 and 260 (worldwide, 260, rather than 270, is +2SD); this is up from 224 and 22, respectively, from December 2012.

The Step 1 score is frequently used in medical residency applications as a measure of a candidate's likelihood to succeed in that particular residency (and on that specialty's board exams), and it has been cited by residency program directors as their most important criterion in selecting graduating medical students for their residency program. Average USMLE Step 1 scores 
for various residencies are available in Charting Outcomes in the Match. Averages for graduates of U.S. medical schools who matched into residency range from 213 for a Family Medicine to 249 for Plastic Surgery.

If the student passes the exam, he or she may not repeat it to achieve a higher score, and any failed attempt is permanently recorded. This “one-time deal” situation is the reason the Step 1 is unanimously viewed as the most arduous and paramount examination a medical student will ever sit during his or her entire career. It has substantial bearing on the specialties and location a residency applicant is competitive for ${ }^{5}$.

\section{Step 2}

USMLE Step 2 is designed to assess whether medical school students or graduates can apply medical knowledge, skills and understanding of clinical science essential for provision of patient care under supervision. US medical students typically take Step 2 during the fourth year of medical school. Step 2 is further divided into two separate exams.

\section{Step 2-CK}

USMLE Step $2 \mathrm{CK}$ is designed to assess clinical knowledge through a traditional, multiple-choice examination. It is a 9 hour exam consisting of 8 blocks of approximately 44 questions each. One hour is given for each block of questions. The subjects included in this exam are clinical sciences like Medicine, Surgery, Pediatrics, Psychiatry and Obstetrics \& Gynecology.

\section{Step 2-CS}

USMLE Step 2 CS is designed to assess clinical skills through simulated patient interactions, in which the examinee interacts with standardized patients portrayed by actors. Each examinee faces 12 Standardized Patients (SPs) and has 15 minutes to complete history taking and clinical examination for each patient, and then 10 more minutes to write a patient note describing the findings, initial differential diagnosis list and a list of initial tests. Administration of the Step 2-CS began in 2004. The examination is only offered in five cities across the country:

Before 2004, a similar exam, the Clinical Skills Assessment (CSA) was used to assess the clinical skills of foreign medical graduates ${ }^{6}$.

\section{Step 3}

USMLE Step 3 is the final exam in the USMLE series designed to assess whether a medical school graduate can apply medical knowledge and understanding of biomedical and clinical science essential for the unsupervised practice of medicine. Graduates of US medical schools typically take this exam at the end of the first year of residency. Foreign medical graduates can take Step 3 before starting residency in about ten U.S. states.

Step 3 is a 16 hour examination divided over two days. Each day of testing must be completed within eight hours.

The first day of testing includes 336 multiple-choice items divided into 7 blocks, each consisting of 48 items. Examinees must complete each block within sixty minutes.

The second day of testing includes 144 multiple-choice items, divided into 4 blocks of 36 items. Examinees are required to complete each block within forty-five minutes. Approximately 3 hours are allowed for these multiple-choice item blocks. Also on the second day are twelve Clinical Case Simulations, where the examinees are required to 'manage' patients in real-time case simulations. Examinees enter orders for medications and/or investigations into the simulation software, and the condition of the patient changes. Cases are of 10 or 20 minutes.

Approximately forty-five minutes to one hour is available for break time on each of the two days of testing?.

\section{Format}

The USMLE first started out as a paper examination, converting to a computer based multiple choice examination. The test can be taken at Prometric test centers worldwide. However, the Step 2 CS and the Step 3 can only be taken in the USA. The software used to administer the test, the NBME FREDtm, was upgraded in 2008 to a new version, FREDtm V2. The implementation of this changeover continues.

\section{Performance}

Grade point average in undergraduate science courses and performance on the MCAT, particularly the biological sciences and physical sciences sections, are strong predictors of performance on the USMLE step 1 
and step 2 exams, though it is unclear whether the verbal reasoning portion of the MCAT has any predictive value. The selectivity of undergraduate institution is also a predictor of step 1 and step 2 performance, even when controlling for undergraduate GPA and MCAT score ${ }^{8}$.

\section{B.Assessing specialist medical education and training in Australia}

The Australian Medical Council (AMC) has assessed and accredited specialist medical education and training and professional development programs since 2002. From 2002 to July 2010, the AMC process for accreditation of specialist education and training programs was a voluntary quality improvement process in which all specialist colleges had agreed to participate. From 1 July 2010, the process is mandatory. The Health Practitioner Regulation National Law Act 2009 makes the accreditation of specialist training programs an element of the process for approval of programs for the purposes of specialist registration. Similarly, the Medical Board of Australia's registration standards indicate that continuing professional development programs that meet AMC accreditation requirements also meet the Board's continuing professional development requirements ${ }^{9}$.

While this is an Australian process, the Medical Council of New Zealand uses AMC accreditation reports to assist it to make decisions about recognising medical training programs in New Zealand. The AMC works with the Medical Council of New Zealand in reviewing binational training programs.

The AMC's Specialist Education Accreditation Committee oversees the accreditation process. The Committee's roles are:

developing guidelines, policy and procedures for the accreditation of specialist medical education and training programs

- Overseeing the AMC's program of accreditation

- Encouraging improvements in postgraduate medical education that respond to evolving health needs and practices, and educational and scientific developments.

AMC accreditation is based on self and peer assessment. Assessments are conducted by AMC teams which report to the Specialist Education Accreditation Committee. Teams include a mix of clinicians, specialist trainees, scientists, allied health professionals, health administrators and wider community perspectives.

Current standards for specialist medical programs The AMC may grant accreditation if it is reasonably satisfied that a specialist medical program and the training organization meet the approved accreditation standards. It may also grant accreditation if it is reasonably satisfied that the training organization and the specialist medical program substantially meet the approved accreditation standards, and the imposition of conditions will ensure the program meets the standards within a reasonable time.

The AMC endorsed revised standards in June 2008, which have applied to all accreditation assessments from 1 January 2009. In 2010, the AMC consulted widely on minor changes to the accreditation standards. Most of these changes were intended to bring specific standards into line with the registration requirements of the Medical Board of Australia. The Medical Board of Australia approved the accreditation standards with these changes on 15 December $2010^{9},{ }^{10}$.

It is important to note that qualifying AMC does give the license to be a Specialist until appropriate training of that specialty is fulfilled.

In its standards, the AMC defines the broad goals of education and training of medical specialists as follows:

1. To produce medical specialists who:

o have demonstrated the requisite knowledge, skills and professional attributes necessary for independent practice through a broad range of clinical experience and training in the relevant specialty

o can practise unsupervised in the relevant medical specialty, providing comprehensive, safe and high quality medical care, including in the general roles and multifaceted competencies inherent in all medical practice and within the ethical standards of the profession and the community they serve.

2. To produce medical specialists with a high level of understanding of the scientific and evidence base of the discipline.

3. To produce medical specialists able to provide leadership in the complex health care environments 
in which they practice, who work collaboratively with patients and their families, and the range of health professionals and administrators, and who accept responsibility for the education of junior colleagues.

4. To produce medical specialists with knowledge and understanding of the issues associated with the delivery of safe, high quality and cost effective health care within the Australian or New Zealand health system.

5. To prepare specialists able to assess and maintain their competence and performance through continuing professional education, the maintenance of skills and the development of new skills.

\section{AMC accreditation procedures}

The way in which the AMC manages the accreditation process, the procedures for assessing individual training programs and the accreditation decisions made by the AMC are explained in Procedures for Assessment and Accreditation of Specialist Medical Education Programs and Professional Development Programs by the Australian Medical Council 2013.

The AMC completed a review of its accreditation procedures in 2011 to ensure that they comply with theHealth Practitioner Regulation National Law. It also streamlined and clarified some processes based on its experience. Revisions were also made to accommodate the memorandum of understanding between the AMC and the Medical Council of New Zealand.

Periodic reports by accredited training organisations Between formal accreditations, the AMC monitors developments in education and training and professional development programs through periodic reports from the accredited training organisations. This requirement ensures that the AMC remains informed of responses to issues raised in the accreditation report, new developments, and issues that may affect the training organisation's accreditation.

\section{Reports are normally required annually ${ }^{10}$.}

\section{C.Post graduate medical education in South Asia}

Time to move on from the postcolonial era undergraduate and postgraduate education increased rapidly in the post-independence era in South Asiaexcept for Bhutan and the Maldives, which do not have medical schools. Now in India alone, act 351, 136 medical schools admit more than 6000 trainees into postgraduate programmes ${ }^{11}$.

Satisfaction over the numbers who have completed postgraduate education conceals the challenges facing the region. Specialist training is in the traditional apprenticeship style rather than an appraisal based approach. Selection of assessment tools is not governed by modern educational theory. Some postgraduate examinations rely on outmoded assessments, such as essays and long cases. Training in research, ethical issues, concepts of team work, and management is variable. Standards for accreditation are ill defined and not uniformly applied. Training programmes are rarely subjected to external review or internal quality control. National medical councils, expected to set and maintain standards, have failed to introduce quality assurance measures on a par with the UK's General Medical Council or the Liaison Commission on Medical Education in the United States.

Some countries and institutes, however, have initiatives to meet these challenges. The Postgraduate Institute of Medicine of Sri Lanka, the College of Physicians and Surgeons of Pakistan and Bangladesh College of Physicians and Surgeons invite external examiners for their final examinations, mostly from UK royal colleges but also from Australia, India, Singapore, and New Zealand. External examiners also review study programmes, and provide training to local educators. Trainees at the specialist registrar level at the Sri Lankan institute must complete a year of training in an approved centre in the United Kingdom, Australia, New Zealand or Singapore. These measures have helped challenge and maintain standards. In Bangladesh all postgraduate courses at state medical schools are subject to quality control $^{12}$.

India is reaping the benefits of the foresight of leaders such as Pundit Jawaharlal Nehru, who made considerable investments in developing science and technology — after independence — albeit from a meagre budget. Subsequent government policies have ensured that India is studded with centrally supported - and regulated-institutes of postgraduate excellence in medicine, science, and information technology. Bangladesh, India, and Pakistan also boast numerous centres of excellence devoted to single specialties such 
as cardiovascular disease, endocrinology, ophthalmology, neuroscience, and mental health. What is missing is a system of accreditation for these centres.

In most countries in South Asia, professional colleges and associations supervise a variety of continuing medical education programmes but there is no revalidation process and no system of awarding credits for educational activities. The College of Physicians and Surgeons Pakistan has initiated a dialogue among stakeholders, however, to introduce revalidation, and the Medical Council of India awards grants for such activities. The Sri Lankan experience is that revalidation is not acceptable to all stakeholders. A plan has emerged to set up a national council and district committees for continuing professional development by January 2005, and a detailed points scheme is being drawn up.

Every country in the region has a core of medical academics and specialists with a vision of a better system. A region wide group devoted to improving postgraduate education could drive quality improvement. Professional colleges and associations in the region can play an important part through advocacy and raising debate and awareness about issues relating to postgraduate education. And lastly, policy makers at the highest level such as government ministers must be lobbied to encourage policies that will drive change. Otherwise, any optimism about medical education in the region will remain unfulfilled ${ }^{13}$.

A nut shell out line of assessment about Pakistan, The College of Physicians and Surgeons of Pakistan offer the post graduate diploma FCPS which is the main stream. Course is 4-5 years with FCPS-I. IMM, FCPS -II required a dissertation to submit before examination .MD \& MS are also present as well.

In India 5 to 7 years MD/MS is the only post graduate degree for all general subjects. After MD/MS only a post graduate doctor can opt for super specialties which is designated as DM of 2 to 3 years. To become a super specialist it requires 8 to 10 years.

\section{UK, Ireland and some Commonwealth countries:} The entry-level first professional degree in these countries for the practice of medicine is that of Bachelor of Medicine and Bachelor of Surgery (MBBS, MB, MB
BCh BAO, BMBS, MBBChir, or MBChB). This degree typically requires between four and six years of study and clinical training, and is equivalent to the North American MD degree. Due to the UK code for higher education, first degrees in medicine comprise an integrated programme of study and professional practice spanning several levels. These degrees may retain, for historical reasons, "Bachelor of Medicine, Bachelor of Surgery" and are abbreviated to MBChB or $\mathrm{MBBS}^{14}$.

In the UK, Ireland and many Commonwealth countries, the M.D. is a postgraduate research degree in medicine. At some universities, this takes the form of a first doctorate, analogous to the Ph.D., awarded upon submission of a thesis and a successful viva. The thesis may consist of new research undertaken on a full- or part-time basis, with much less supervision (in the UK) than for a Ph.D., or a portfolio of previously published work.

\section{Postgraduate education and training in UK}

After medical students graduate they enter a two-year Foundation Programme. After that, they choose to train either for another three years to become a GP or longer to become a specialist consultant.

The GMC decides whether or not to approve curricula and assessment systems, training programmes, GP trainers, and posts held by these trainees.

To do this, GMC set requirements for postgraduate medical education and training and test whether or not these requirements are being met through quality assurance activity.

GMC arrange for experts to visit the deaneries, inspect what goes on, and discuss local arrangements. It also publish what is founded out on the website. GMC also consider reports from the postgraduate deaneries that organise training and the medical royal colleges that set curricula and organize examinations ${ }^{15}$.

The organizer survey trainees and trainers, and receive information from other regulators. It also respond to concerns raised by trainees, deaneries, local education providers, patients or others, and arrange additional checks of deaneries if there is evidence that requires investigation 
Information for patients and the public

NHS Medical Career Grades

\begin{tabular}{|c|c|c|c|c|}
\hline & \multicolumn{2}{|c|}{ Old system } & \multicolumn{2}{|c|}{$\begin{array}{l}\text { New system (Modernising Medical } \\
\text { Careers) }\end{array}$} \\
\hline Year 1: & \multicolumn{2}{|c|}{$\begin{array}{l}\text { Pre-registration house } \\
\text { officer (PRHO) - one year }\end{array}$} & \multicolumn{2}{|c|}{$\begin{array}{l}\text { Foundation Doctor (FY1 and FY2) - } 2 \\
\text { years }\end{array}$} \\
\hline Year 2: & \multirow{2}{*}{\multicolumn{2}{|c|}{$\begin{array}{l}\text { Senior house officer (SHO) } \\
\text { a minimum of two years, } \\
\text { although often more }\end{array}$}} & & \\
\hline Year 3: & & & \multirow{4}{*}{$\begin{array}{l}\text { Specialty } \\
\text { Registrar (StR) } \\
\text { in a hospital } \\
\text { speciality: } \\
\text { minimum six } \\
\text { years }\end{array}$} & Specialty \\
\hline Year 4: & \multirow{3}{*}{$\begin{array}{l}\text { Specialist } \\
\text { registrar } \\
\text { four to six } \\
\text { years }\end{array}$} & $\begin{array}{l}\text { GP registrar- } \\
\text { one year }\end{array}$ & & $\begin{array}{l}\text { in general practice: } \\
\text { three years }\end{array}$ \\
\hline Year 5: & & \multirow{3}{*}{$\begin{array}{l}\text { General } \\
\text { practitioner } \\
\text { total time in } \\
\text { training: } 4 \\
\text { years }\end{array}$} & & \\
\hline $\begin{array}{l}\text { Years 6- } \\
\text { 8: }\end{array}$ & & & & $\begin{array}{l}\text { General practitioner } \\
\text { total time in }\end{array}$ \\
\hline Year 9: & $\begin{array}{l}\text { Consultant } \\
\text { total time in } \\
\text { training: } \\
\text { minimum 7- } \\
9 \text { years }\end{array}$ & & $\begin{array}{l}\text { Consultant } \\
\text { total time in } \\
\text { training: } \\
\text { minimum } 8 \text { years }\end{array}$ & 5 years \\
\hline Optional & \multicolumn{2}{|c|}{$\begin{array}{l}\text { Training may be extended by } \\
\text { pursuing } \\
\text { medical research (usually } \\
\text { two-three years), } \\
\text { usually with clinical duties } \\
\text { as well }\end{array}$} & \multicolumn{2}{|c|}{$\begin{array}{l}\text { Training is competency based, times } \\
\text { shown are a minimum. } \\
\text { Training may be extended by obtaining } \\
\text { an Academic Clinical } \\
\text { Fellowship for research or by dual } \\
\text { certification in another speciality. }\end{array}$} \\
\hline
\end{tabular}

NHS Medical Career GradesOld system New system (Modernising Medical Careers)Year 1:Preregistration house officer (PRHO) - one yearFoundation Doctor (FY1 and FY2) - 2 yearsYear 2:Senior house officer (SHO) a minimum of two years, although often moreYear 3: Specialty Registrar (StR) in a hospital speciality:minimum six years Specialty Registrar (GPST) in general practice:three years Year 4:Specialist registrarfour to six years GP registrar- one yearYear 5:General practitionertotal time in training: 4 yearsYears 6-8:General practitionertotal time in training:5 yearsYear 9:Consultanttotal time in training:minimum 7-9 years Consultanttotal time in training:minimum 8 years Optional Training may be extended by pursuingmedical research (usually twothree years), usually with clinical duties as wellTraining is competency based, times shown are a minimum. Training may be extended by obtaining an Academic ClinicalFellowship for research or by dual certification in another speciality.

In order to be eligible to apply for an M.D. degree from a UK or Commonwealth University one must hold either an MBBS, MBChB, or an equivalent US-MD degree and must usually have at least 5-years of postgraduate 
experience. Therefore graduates from the MBBS or MBChB degrees do not hold doctorates; however, physicians holding these degrees are referred to as 'Doctor' as they are fully licensed as medical practitioners. In some commonwealth nations these interns are designated as House Officers ${ }^{16}$.

In the UK assessment of clinical diploma is being handled by the ROYAL COLLEGES known as Membership. Presently this is no more exit exam unlike before. After achieving Membership the candidates must go through the CCT (Comprehensive Clinical Training) program which varies from subjects to subjects 4 to 8 years ${ }^{17}$.

\section{Bangladesh}

Our father of the nation Bangubandhu Sheik Mujibar Rahman took a far sighted vision with in six month of our liberation by establishing Bangladesh College of Physicians and Surgeons. In Bangladesh we have Fellowship (FCPS) in different subject since 1972 assessed by BCPS (Bangladesh College of Physicians and Surgeons) an examining body. There were no other equivalent diploma in clinical medicine except in few subjects (DCH, D-Card, DTCD etc.) and in basic subjects M-Phil at that time. FCPS for general subjects requires 4 years training but subspecialty requires 5 years for appearing examination. FCPS -I, FCPS Preliminary, FCPS- II are the steps. It is an exit exam. Dissertation/thesis submission is a pre requisite before appearing in the final examination.

In mid 1980's MD \& MS came as parallel degree in clinical medicine there after in non clinical subjects.

Assessment process in Fellowship grossly differs from that of the MD \& MS.The assessment system in fellowship is training based and log book based day to day system where the supervisor is observing the qualiy assessment and control of the trainee in second part. In 2010 the Residency Program started at Bangabandhu Sheikh Mujib Medical University (BSMMU) for the first time and then all Medical Colleges brought under the umbrella of BSMMU to start residency program of 5 years (MD \& MS) duration. The residency program is consisting with phase A and phase B where phase A is based on core medical training for two years with structures assessment system including portfolio based and $\log$ book based assessment with similar assessment system in phase $B$ for the specialty subjects. In addition thesis is also to be undertaken in phase B.
After having FCPS / MD / MS the graduate become post graduate doctor and gain equal access for appointment and promotion. The basic difference of MD and MS program in Bangladesh with other country is that the candidate can choose any subspecialty topic after graduation while in developed country the MD is basically for core subjects of Medicine, Surgery and Obs and Gynaecology while the subspecialty will be chosen after gaining the MD or MS degree.

As on July 2014 the total passed candidate (exit exam) in FCPS is between 12-15 percent. In MD /MS new program (Residency for 5 years) no batch yet exit so no data is available.

\section{Conclusion:}

Worldwide the assessment system varies but there is a uniformity of assessment . In Bangladesh multiple assessment system creates professional problem or is other word some are easy some are tough. Ministry of Health can play an important role by creating national core body who will find out the uniform assessment system accreditation process so that we will have healthy health professional assessment system.

\section{References:}

1. World Health Assembly. Reorientation of Medical Education and Medical Practice for Health for All. WHA Resolution 48.8. WHO, Geneva, 1995.

2. WFME Task Force on Defining International Standards in Basic Medical Education, Report of the Working Party, Copenhagen, 14-16 October 1999.

3. Gillian M, Janet S, 'Science', 'critical thinking' and'competence' for Tomorrow's Doctors. A review of terms and concepts, Med Edu. 2000;34:53-60

4. 2010 Bulletin of Information: USMLE. A publication of the FSMB and the NBME. 2009.

5. “2012 Performance Data”. Step 1 Administrations. Federation of Medical State Boards. 2013. Retrieved 6 October 2013.

6. http://www.nrmp.org/data/programresultsbyspecialty.pdf

7. http://medicalopedia.org/2648/usmle-new-changes-2014step-3-going-to-be-divided-into-two-parts/

8. Kleshinski, James; Sadik A. Khuder; Joseph I. Shapiro; Jeffrey P. Gold (7 November 2007). "Impact of preadmission variables on USMLE step 1 and step 2 performance". Advances in Health Science Education (Springer) 14: 69 78. doi:10.1007/ s10459-007-9087-x. Retrieved August 22, 2010.

9. http:// standardsreview@amc.org.au 
10. Australian Medical Council. Guidelines for the Accreditation of Medical Specialist Education and Training and Professional Development Programs. Australian Medical Council, Canberra, 2010.

11. Fred T, Myrra VD, Anneke K, Richard G, Ben B. Behavioral elements of professionalism: Assessment of a fundamental concept in medical care, Med Teach. 2010; 32: e161-e169.

12. Shiwani MH. A structured and standardized national postgraduate medical trading policy: need of the time. J Pak Med Assoc 2007; 57:472-4.

13. Biggs JSG. Postgraduate medical training in Pakistan: observations and recommendations. J Coll Physicians Surg Pak 2008;18(1):58-
14. Commission of the European Communities.Fourth Report and Recommendations on the Conditions for Specialist Training. Doc. XV/E/8306/3/96-EN. Brussels, 1997.

15. Commission of the European Communities. Fourth Report and Recommendations on the Conditions for Specialist Training. Doc. XV/E/8306/3/96-EN. Brussels, 1997.

16. Sargeant J, Eva KW, Armson H, Chesluk B, DornanT, Holmboe E, et al. Features of assessment learners use to make informed self - assessments of clinical performance. Med Edu. 2011; 45: 636-647.

17. General Medical Council. Good Medical Practice. 4rd Edition. Generaln Medical Council. London. http://www.gmc-uk.org, 2010. 